\title{
Applying The ARCS Motivation Model In Technological And Vocational Education
}

Hung-Chang Liao, Chung-Shan Medical University Ya-huei Wang, Chung-Shan Medical University

\begin{abstract}
This paper describes the incorporation of Keller's ARCS (Attention, Relevance, Confidence, and Satisfaction) motivation model into traditional classroom instruction-learning process. Viewing that technological and vocational students have low confidence and motivation in learning, the authors applied the ARCS motivation model not only in the instructional design phase but also in the classroom instruction process of technological and vocational education. The purpose of the study is to demonstrate whether the application of ARCS motivation model to instructional design and classroom instruction of technological and vocational education could bring positive effects on students' satisfaction in terms of instruction objective, instruction material/method, teacher's qualities, class climate/environment, assessment, and overall satisfaction.
\end{abstract}

Keywords: ARCS motivational model, technological and vocational education, student satisfaction

\section{INTRODUCTION}

$\mathscr{R}$

Tesearch has shown that technological and vocational students have been sluggish during their learning process [1][9][11]. Bearing the mark of low-achievers and slow-learners, they do not have much intention, motivation, or confidence while acquiring professional knowledge. Hence, even though the curriculum design is based on wholesome instructional principles, if students have neither motivation nor ambition to fulfill their learning goals, all the instruction-learning process is in vain, becoming wasting time to both instructors and students.

If technological and vocational students can be motivated, they would be willing to "actively" attend to classroom instructions and get engaged in instruction-learning activities. Conversely, if they cannot get motivated in the instruction-learning process, they would not be willing to put forth their best effort to learn. Instead, they would keep passive or even absent-minded during the classroom instruction-learning process.

This paper describes the incorporation of Keller's ARCS (Attention, Relevance, Confidence, and Satisfaction) motivational model into traditional classroom instruction-learning process for technological and vocational students. The purpose of the study is to demonstrate whether the application of ARCS motivational model to instructional design and classroom instruction of technological and vocational education could bring positive effective on students' satisfaction in terms of instruction objective, instruction material/method, teacher's qualities, class climate/environment, assessment, and overall satisfaction. Furthermore, motivational strategies based on Keller's ARCS model are offered to make the whole instruction responsive to individual students' interests and needs to further enhance their desire for pursuing learning achievement.

\section{LEARNING MOTIVATION}

It is impossible to motivate students if students have neither motive nor desire to accomplish their learning task [6]. However, it could be possible for teachers to create or transform the learning environment in which students themselves could arouse their attention, motivation, and confidence to learn and increase their interest in learning. In his book Powerful Principles of Instruction, Stephen, Yelon [12] mentioned about four common attributes of 
being an excellent instructor:

- $\quad$ An excellent instructor should care about the subject matters they teach.

- $\quad$ An excellent instructor should care about their students' learning and keep the positive attitude that their students have the ability to learn.

- $\quad$ An excellent instructor should not only care about their teaching jobs but should also further enjoy the process of analyzing, planning, and improving their teaching techniques.

- $\quad$ An excellent instructor should apply motivational strategies they know and incorporate them into instruction process in order to make their instruction effective.

From these above attributes, it is obvious that teachers as well as motivation play an important role in affecting students' success in learning performance.

\section{COMPONENTS OF KELLER'S ARCS MOTIVATION MODEL}

In 1979, Keller developed the ARCS model of motivation to make the instruction more interesting and to enhance students' motivation [2]. The ARCS motivational model is the first model trying to incorporate motivation into the systematic instruction design process. There are four categories in the ARCS motivation model: Attention, Relevance, Confidence, and Satisfaction. If the subject matters can catch students' attention and is connected to students' prior knowledge or current experience, students would be satisfied in the learning process, feeling secured and confident in mastering the subject matters. Hence, it is necessary to take the four components-attention, relevance, confidence, and satisfaction - into consideration during instructional design in order to create an optimal learning environment in which students would feel comfortable and motivated to learn.

Based on Keller's ARCS motivation model, in the instruction design process, instructors should always remind themselves to arouse and sustain students' curiosity and attention [5][7][10]. In addition, the instruction material must be connected to students' needs and learning goals in order to let students be motivated and have confidence in success, foreseeing positive learning outcomes. Hence, students can derive satisfaction and a sense of achievement with the interaction of instruction and learning.

\section{APPLYING THE ARCS MOTIVATION MODEL IN TECHNOLOGICAL AND VOCATIONAL EDUCATION}

The main purpose of the Keller's ARCS motivation model in the instructional design is to motivate students' learning ambition. In this paper, viewing that technological and vocational students have low confidence and motivation in learning [9], the authors intend to apply the ARCS (Attention, Relevance, Confidence, and Satisfaction) motivation model not only in the instructional phase but also in the classroom instructional process of technological and vocational education. When designing instruction, instruction designers or teachers may keep in the mind the ARCS motivation model. However, in the substantial classroom instruction, it is impossible to predict students' background and diversity. Therefore, a preset instructional design would not be suitable to each individual student. Therefore, it is necessary to keep infusing the four elements of the ARCS model into classroom instruction.

With the incorporation of ARCS motivation model into the instructional-learning process, technological and vocational students would be cared, motivated, and further channelled into their appropriate ways of learning process. The four components of ARCS model-Attention, Relevance, Confidence, and Satisfaction - are further described as follows.

- Attention: Based on Keller's research [2-6][7-8][10], attention is the first prerequisite key to motivate students' learning process. If teachers cannot catch students' attention, the whole instruction would become invalid. In order to arouse technological and vocational students' interest and curiosity, during the classroom instruction process, instructors should use different teaching devices to help stimulate their curiosity and sensation seeking, such as using perceptual arousal and inquiry arousal [3]. Moreover, they may use various visual or audio media, such as films, CD-ROMs, etc., to gain these students' attention. 
- Relevance: Relevance is defined as meeting each individual student' needs and goals so that a positive attitude toward instruction would be aroused [4]. In order to catch technological and vocational students' attention, the instructional material should be related to their personal career goal which plays a key to determine whether they would be motivated or willing to continue paying attention to classroom instruction-learning. Hence, in order to arouse technological and vocational students' positive attitude toward classroom instruction, teachers should apply a series of teaching materials, instruction techniques, and activities relevant to learners' past experiences, prior knowledge, current interests, future expectation, or career goals.

- Confidence: Confidence is defined as students' "positive expectancy for success" [6]. Without confidence, students would not be willing to participate in the learning process. However, if technological and vocational students can foresee the possibility of positive expected learning outcomes, they would feel comfortable and confident in the learning process. In other words, the challenge's difficulty should be within students' acceptable range of difficulty, and with the foreseen success, students would not hesitate to keep going ahead to reach their learning goals. Otherwise, they may lose confidence and hence lose their interest in instruction-learning process. Therefore, in order to spur technological and vocational students' confidence, during classroom instruction, teachers should provide support to individual students' needs, such as instructional assistance and learning tools.

- Satisfaction: Satisfaction serves as the final motivation component in the ARCS motivational model. In order to keep technological and vocational students remaining motivated in instruction-learning process, teachers should let students feel satisfied with the procedure and outcomes of classroom instruction. If classroom instruction-learning process is interesting, challenging, and rewarding, students would not only be motivated but also feel positive about their devotion and achievement. For that reason, teachers should always remind themselves to consider each individual student's needs and to provide immediate feedback, such as praise and problem-solving interaction, to decrease students' confusion and to increase their immediate satisfaction.

\section{METHOD}

In order to explore the effects of the application of ARCS motivational model to technological and vocational students, two classes, 93 students were selected as the experimental sample. By flipping of the coin, the class of 1A, 45 students, was chosen as the experimental group, while the class of $2 \mathrm{~A}, 48$ students, was chosen as the control group. The teaching material used in this study was technological and engineering education. The experimental group went through the ARCS motivation model, while the control group did not. The experiment was implemented for twelve weeks, two hours a week. After the twelve-week experimental intervention, both groups were required to fill out a post-experimental student satisfaction questionnaire rated on 5-point Likert-type scale ranging from strongly disagree to strongly agree. The questionnaire was first reviewed by three experienced English teachers. Table 1 shows the pretest-posttest experimental design. In Table $1, \mathrm{O}_{1}$ stands for the pretest experimental group, while $\mathrm{O}_{3}$ stands for the pretest control group. $\mathrm{O}_{2}$ stands for the posttest experimental group, while $\mathrm{O}_{4}$ stands for the posttest control group. $\mathrm{X}_{1}$ refers to the application of the ARCS motivation model.

Table 1: The pretest-posttest experimental design

\begin{tabular}{cccc}
\hline Group & Pretest & Treatment & Posttest \\
\hline Experimental & $\mathrm{O}_{1}$ & $\mathrm{X}_{1}$ & $\mathrm{O}_{2}$ \\
\hline Control & $\mathrm{O}_{3}$ & & $\mathrm{O}_{4}$ \\
\hline
\end{tabular}

\section{RESULTS}

This study used Cronbach's Alpha to test the interior reliability within each category of the questionnaire. The reliability coefficients for the categories in the student satisfaction questionnaire are shown in Table 2. 
Table 2: Reliability coefficients/Cronbach's Alpha for the categories in the student satisfaction questionnaire

\begin{tabular}{ccc}
\hline Category & Control Group & Experimental Group \\
\hline $\begin{array}{c}\text { Instructional } \\
\text { Objective }\end{array}$ & 0.7473 & 0.8454 \\
\hline $\begin{array}{c}\text { Instructional } \\
\text { Material/Method }\end{array}$ & 0.8310 & 0.8591 \\
\hline $\begin{array}{c}\text { Teacher's } \\
\text { Qualities }\end{array}$ & 0.9017 & 0.7991 \\
\hline $\begin{array}{c}\text { Class } \\
\text { Climate }\end{array}$ & 0.8335 & 0.9076 \\
\hline Assessment & 0.8934 & 0.8500 \\
\hline Overall & 0.9413 & 0.9356 \\
\hline
\end{tabular}

In addition, examined by t-tests, the results of both groups' overall satisfaction are illustrated on Table 3.

Table 3: Independent $t$-test result of the student satisfaction questionnaire

\begin{tabular}{|c|c|c|c|c|c|}
\hline Test & Group & Mean & S.D. & $\mathrm{t}$ & p-value \\
\hline Instructional & Experiment & 11.71 & 1.46 & & $0.001 * *$ \\
\hline Objective & Control & 10.44 & 2.05 & 3.469 & \\
\hline Instructional & Experiment & 56.76 & 6.66 & \multirow[b]{2}{*}{4.096} & $0.000 * *$ \\
\hline Material/Method & Control & 50.10 & 8.77 & & \\
\hline Teacher' & Experiment & 21.38 & 3.05 & & $0.000 * *$ \\
\hline Qualities & Control & 18.35 & 2.59 & 4.362 & \\
\hline Class Climate/ & Experiment & 32.82 & 4.02 & & $0.000 * *$ \\
\hline Environment & Control & 28.75 & 4.88 & 4.374 & \\
\hline \multirow[t]{2}{*}{ Assessment } & Experiment & 16.16 & 2.23 & 3.483 & $0.001 * *$ \\
\hline & Control & 14.40 & 2.62 & & \\
\hline \multirow[t]{2}{*}{ Overall } & Experiment & 138.82 & 14.53 & 4.633 & $0.000 * *$ \\
\hline & Control & 122.04 & 19.80 & & \\
\hline
\end{tabular}

Experimental group: $\mathrm{N}=45$; control group: $\mathrm{N}=48$

S.D.=Standard Deviation

$* * P<0.01$

\section{DISCUSSION}

It cannot be denied that the ultimate goal of education is to foster continuous growth in every student in order to prepare him or her for future career development. In this paper, the authors hope that the description of the ARCS - Attention, Relevance, Confidence, and Satisfaction-motivation model could not only be incorporated with the traditional curriculum and instruction design but also be implemented in class instruction process to enhance students' motivation to learn. If the learning issue can attract students' attention and is relevant to students' past or current experience, then students would feel secured and confident in mastering topics and further feel satisfied [4]. Furthermore, it is known that even with a well-sound curriculum and instructional design, it is possible that students cannot be motivated by classroom instruction-learning process and cannot further participate in classroom interaction. Consequently, the whole instruction-learning process would become a waste of time to both instructors and students. With the modified ARCS motivation model being applied to both the pre-contemplating phase of instructional design and to the subsequent practical implementing phase of class instruction, instructors could early spot students' learning problem and make an early instruction intervention to further appropriately modify teaching strategies to meet various learners' needs. 
It has been proved that ARCS motivation model is useful in instruction planning [5][7-8][10]. With an eye to holding students' attention, instruction designers should design learning units based on students' prior experiences and relevant interest in order to develop students' confidence and further grant satisfaction from the outcome of instruction. However, any groups of learners are not homogeneous. Nowadays students come from diverse educational, socioeconomic, or ethical backgrounds. Hence, instructors can never identify or presee students' learning behavior and would never know whether their preset instructional design and teaching can meet student learning needs, unless once being involved in classroom instruction. It would become impossible to let a preset instructional design fit for each individual student's need. Therefore it is necessary to implement the ARCS motivation model not only to the preset instructional design but also to the afterward class instruction. After applying the A-R-C-S in instructional design process and later getting involved in class interaction, in order to know more about each individual learner's needs and to address each learner's particular motivational needs, instructors should further modify the A-R-C-S used in instructional design and implement a continuously cycled A-R-C-S in substantial classroom instruction with an eye to letting students continuously interact with and benefit from instruction which instructors provide in class. Then, after assessing students' performance, which also involves additional response feedback occasions, both instructors and instruction designers can base on the feedback to adjust the future instructional objective, curriculum design, instructional design, and further class instruction. Hence, the whole instructional system based on modified ARCS motivation model would become a feedback loop, which could be modified any time according to the substantial classroom instruction.

Hence, while through the subsequent application of the ARCS motivational model in the phase of classroom instruction implementation, instructors, after analyzing each individual student's need and learning style, could modify or use different teaching methods, such as team study, individualized study, or cooperative study, to different students in order to keep motivating them and maximizing the learning outcome of each individual, not just limiting to some certain students' needs. A sound instructional design facilitates students' learning motivation, while a continuous adjustment and modification of class instruction to meet individual students' needs would keep individual students stimulating all the time and further channelling them to learn by themselves.

Through continuously capturing and holding students' attention, offering instructional content relevant to students' personal experiences, giving students confidence to master their learning tasks, and then letting them obtain satisfaction, the continuous integration of the ARCS motivation model into curriculum design and classroom instruction process will keep motivating technological and vocational school students to "actively" engage in instructional and learning process. Hence, under the ARCS motivation model, the students would become not only active learners but also instructors' partners in instructional interaction.

On the other hand, in the process of ARCS-interactive instructional process, instructors should function as carer, facilitator, and monitor. Therefore, instruction must focus on teachings skills predictive of success. Besides, in order to let students participate in the classroom interaction, instructors, with preset instructional plan to motivate students' initial success, should also monitor instructional conditions and paces during initial instruction and then based on the classroom feedback, appropriately modify their teaching techniques in classroom to maintain and reinforce students' ambition to the way to success. In addition, they should care for and identify students' learning problems with an eye to improving their learning conditions. Furthermore, based on these students' feedback, technological and vocational school instructors could conditionally apply one-to-one instruction, small-group instruction, or whole-class instruction in classroom instruction to maximize students' learning outcome. Under this condition, both teachers and students would engage in a continuous A-R-C-S (attention-relevance-confidence-satisfaction) motivational cycle of assessment, planning, and instructional intervention that matches each unique student's need with appropriate individualized instruction.

\section{REFERENCE}

1. Hsieh, Y., Hwang, G., and Liu, G., (2003) A case study on the investigation for connections of affecting students' learning attitudes. J. of National Huwei Institute of Technology, 6, 99-110.

2. Keller, J. M., (1979) Motivation and instructional design: A theoretical perspective. J. of Instructional Development, 2, 24, 26-34. 
3. Keller, J.M., (1983) Motivational design of instruction. In: Reigeluth, C.M. (Ed.), Instructional Theories and Models: An Overview of Their Current Status (pp. 33-434). New York: Lawrence Erlbaum Associates.

4. Keller, J.M., (1987) Development and use of the ARCS model of instructional design. Journal of Instructional Development, 1, 3, 2-10.

5. Keller, J.M., (1992) Enhancing the motivation to learn: origins and applications of the ARCS model. Reports from the Institute of Education, Tohoku Gakuin University, 11, 45-67.

6. Keller, J.M., and Kopp, T., (1987) Application of the ARCS model of motivational design. In: Reigeluth, C.M. (Ed.), Instructional Theories in Action: Lessons Illustrating Selected Theories and Models. Lawrence Erlbaum Associates, U.S.A.

7. Keller, J., and \& Suzuki, K., (1988) Uses of the ARCS motivation model in courseware design. In: Jonassen, D. (Ed.), Instructional Designs for Microcomputer Courseware (pp. 401-434). Hillsdale, NJ: Lawrence Eribaum Associates.

8. Popovish, N.G., (2000) Applying the ARCS model of motivational design to pharmaceutical education. American Journal of Pharmaceutical Education, 64, 2, 188-196.

9. Su, M.M., (2005) A study of EFL technological and vocational college students' and their self-perceived English proficiency. Electronic J. of Foreign Language Teaching, 2, 1, 44-56.

10. Suzuki, K., and Keller, J.M., (1996) Creation and cross cultural validation of an ARCS motivational design matrix. Paper presented at the annual meeting of Japanese Association for Educational Technology, Kanazawa, Japan.

11. Wu, C.Y., (2001) A promising avenue for improvement in English instruction and general education curricula: An integrated curriculum and theme-based instruction. Paper presented at Elliott Masie's LMS Conf. Multi-Vendor, Las Vegas, U.S.A.

12. Yelon, S.L., (1996) Powerful Principles of Instruction. New York: Longman, White Plains. 